\title{
Expression of Mutated Mouse Myocilin Induces Open-Angle Glaucoma in Transgenic Mice
}

\author{
Vladimir Senatorov, ${ }^{1}$ Irina Malyukova, ${ }^{1}$ Robert Fariss, ${ }^{2}$ Eric F. Wawrousek, ${ }^{1}$ Srividya Swaminathan, ${ }^{3}$ Shyam K.Sharan, ${ }^{3}$ \\ and Stanislav Tomarev ${ }^{1}$ \\ ${ }^{1}$ Section of Molecular Mechanisms of Glaucoma, Laboratory of Molecular and Developmental Biology, and 2Biological Imaging Core, National Eye Institute, \\ National Institutes of Health, Bethesda, Maryland 20892, and ${ }^{3}$ Mouse Cancer Genetics Program, National Cancer Institute, Frederick, Maryland 21702
}

\begin{abstract}
We developed a genetic mouse model of open-angle glaucoma by expression of mutated mouse myocilin (Myoc) in transgenic ( $\mathrm{Tg}$ ) mice. The Tyr423His point mutation, corresponding to the severe glaucoma-causing Tyr437His mutation in the human MYOC gene, was introduced into bacterial artificial chromosome DNA encoding the full-length mouse Myoc gene and long flanking regions. Both wildtype (Wt) and Tg animals expressed Myoc in tissues of the irido-corneal angle and the sclera. Expression of mutated Myoc induced the accumulation of Myoc in cell cytoplasm and prevented its secretion into the extracellular space. The levels of ATPase-1 were reduced in the irido-corneal angle of $\mathrm{Tg}$ mice compared with $\mathrm{Wt}$ animals. Tg mice demonstrated a moderate elevation of intraocular pressure, the loss of $\sim 20 \%$ of the retinal ganglion cells (RGCs) in the peripheral retina, and axonal degeneration in the optic nerve. RGC depletion was associated with the shrinkage of their nuclei and DNA fragmentation in the peripheral retina. Pathological changes observed in the eyes of $\mathrm{Tg}$ mice are similar to those observed in glaucoma patients.
\end{abstract}

Key words: glaucoma; myocilin; transgenic mice; trabecular meshwork; retina; retinal ganglion cells

\section{Introduction}

Glaucoma is a group of neurodegenerative disorders characterized by the death of retinal ganglion cells (RGCs) and degeneration of the axons in the optic nerve. Primary open-angle glaucoma (POAG) is the most common form of glaucoma. Despite the high frequency and severity of this disease, little is known about underlying pathological mechanisms. Because experimental studies of the molecular mechanisms of glaucoma in humans are limited, using animal, cell, and organ models has become a necessity. Animal models of glaucoma are often more advantageous than cell or organ culture models because they may better mimic the physiological responses of the glaucomatous eye to the disease or treatments (Weinreb and Lindsey, 2005).

Although there are considerable differences between mouse and human eyes, mouse models provide powerful genetic tools for studying complex diseases such as glaucoma (John et al., 1999; Weinreb and Lindsey, 2005). Recently, several mouse models of glaucoma were developed and characterized. In particular, DBA/2J mice develop a progressive form of secondary angleclosure glaucoma resembling pigmentary dispersion glaucoma in human (John et al., 1998). A transgenic (Tg) mouse strain with a targeted mutation in the gene for the $\alpha 1$ subunit of collagen type I demonstrates a gradual elevation of intraocular pressure (IOP) and progressive optic nerve axon loss (Mabuchi et al., 2004). Other approaches include cauterization of the episcleral and lim-

Received July 17, 2006; revised Sept. 12, 2006; accepted Sept. 29, 2006.

We thank Drs. Anthony P. Adamis and Lichun Zhong for helping us to set up IOP measurements.

Correspondence should be addressed to Dr. Stanislav Tomarev, National Eye Institute, National Institutes of

Health, Building 7, Room 103, 7 Memorial Drive, MSC 0704, Bethesda, MD 20892-0704. E-mail: tomarevs@nei.nih. DOI:10.1523/JNEUROSCI.3020-06.2006

Copyright $\odot 2006$ Society for Neuroscience $\quad$ 0270-6474/06/2611903-12\$15.00/0 bal veins leading to elevation of IOP and the loss of RGCs (Ji et al., 2005).

It is now well established that a genetic component may contribute to a glaucoma formation. Mutations in the myocilin $(M Y O C)$ gene were found in 3-4\% of patients with POAG (Fingert et al., 2002). Among the identified mutations, the Tyr437His mutation in MYOC is associated with one of the most severe forms of glaucoma for which the average age at diagnosis was 20 years. That is $\sim 40$ years earlier than that caused by the milder MYOC mutations (Alward et al., 1998). The Tyr437His mutation in the human MYOC corresponds to the Tyr423His mutation in the mouse myocilin (Myoc). Previously, we demonstrated that mutated Tyr437His human MYOC and Tyr423His mouse Myoc have similar properties (Malyukova et al., 2006). We also produced $\mathrm{Tg}$ mice expressing high levels of wild-type $(\mathrm{Wt})$ mouse Myoc in the tissues of the eye angle, using bacterial artificial chromosome (BAC) DNA encoding the full-length mouse Myoc gene (Gould et al., 2004). These mice did not develop elevated IOP and did not show any signs of degeneration in the retina and optic nerve. These findings suggest that disease pathogenesis in POAG patients depends on the expression of abnormal mutant proteins (Gould et al., 2004).

In the present study, we produced $\mathrm{Tg}$ mice using previously characterized BAC DNA in which we introduced the Tyr423His mutation into the mouse Myoc gene. These mice demonstrated pathological changes in the eye, which are similar to those observed in glaucoma patients.

\section{Materials and Methods}

$\mathrm{Tg}$ mice. The Tyr423His point mutation ( $\mathrm{T}$ to $\mathrm{C}$ in codon 423) was introduced into BAC DNA \#16652 (Tomarev et al., 2003) using oligonucleotide-based recombining in Escherichia coli (Swaminathan et 
al., 2001; Court et al. 2003). The targeting vector was generated using three primers: a 100mer oligonucleotide with 50-base homology from either side of the region to be modified (SV-163), 5'-CATCCGTAAGCAGTCTGTGGCCAATGCCTTTGTGCTCTGTGGCATCTTGCACACGGTGAGCAGCTACTCTTCAGCCCATGCAACCGTCAACTTTGCCTAC-3'; and two external primers: a forward (SV-164), 5' -TTGAGCGTACCTGGGAGACTAACATCCGTAAGCAGTCTGTGG-3' ${ }^{\prime}$, and a reverse (SV-165), 5' -CTGGTCCCCGTTTTAGTGTCGTAGGCAAAGTTGACGGTTG-3' , each with 20-base overlaps on either side of SV-163. Combination-PCR was performed by mixing $10 \mathrm{ng}$ of SV-163 and $300 \mathrm{ng}$ of SV-164 and SV165 in a $50 \mu \mathrm{l} \mathrm{PCR}$ using the Expand High Fidelity PCR system (Boehringer Mannheim, Indianapolis, IN). The resultant PCR product, a 142-mer targeting cassette, was purified and used in electroporations. After electroporation, cells were resuspended in $1 \mathrm{ml}$ of SOC medium and incubated at $32^{\circ} \mathrm{C}$ for $1.5 \mathrm{~h}$. The cells were serially diluted and plated on chloramphenicol $(25 \mu \mathrm{g} / \mathrm{ml})$-containing LB plates. After $24 \mathrm{~h}$ at $32^{\circ} \mathrm{C}$, 94 individual clones were picked and analyzed by PCR using primers SV-164 and SV165 to obtain a 142 bp product. Because the T-to-C change in codon 423 disrupts an RsaI retriction site, the $142 \mathrm{bp} \mathrm{PCR} \mathrm{product} \mathrm{was} \mathrm{di-}$ gested with RsaI restriction enzyme, and products were examined by gel electrophoresis. Wt PCR product, when digested with RsaI, results in three fragments $(8,64$, and $70 \mathrm{bp})$, whereas the mutant is expected to result in two fragments ( 8 and $134 \mathrm{bp}$ ). Two recombinant clones were identified. The presence of a missense mutation was confirmed in both clones by sequencing.

$\mathrm{Tg}$ mice were produced by injection of mutated BAC DNA into the pronucleus of fertilized mouse FVB/N oocytes. The founders and all subsequent generations were mated to C57BL/6 mice. All experiments were conducted with F5 and later generations. The transgene copy number was estimated by realtime PCR using SYBR Green PCR Master Mix (Applied Biosystems, Foster City, CA) and ABI Prism 7900HT (Applied Biosystems). The following primers were used: forward 5'-GCCTGGGAGAACTTCAACAT-3'; reverse 5'-AGGCATAGAGGCTCCTCACA-3'. To estimate the relative level of mutated Myoc expression, lenses were removed from the eyes of Tg mice, and total RNA was isolated from the rest of the eyes using RNAzol B (Teltest, Friendswood, TX). This RNA was used as a template for cDNA synthesis with SuperScript II Reverse Transcriptase (Invitrogen, Carlsbad, CA). A fragment containing the mutation site was amplified by PCR using the following primers: forward 5'-GTGAGCAGCTACTCTTCAGC-3'; reverse 5'-CTGGACTGCTACACTATGTGA-3'. This fragment was cloned into the pCRII-TOPO vector (TOPO TA Cloning kit; Invitrogen). DNA was isolated from randomly picked clones, and cDNA inserts were sequenced.

In situ hybridization. For in situ hybridization, mouse eyes were fixed in $4 \%$ paraformaldehyde in $0.1 \mathrm{M} \mathrm{PBS}, \mathrm{pH} 7.4$, at $4^{\circ} \mathrm{C}$ overnight and processed for paraffin embedding. Serial sections $(6 \mu \mathrm{m})$ were hybridized with riboprobes labeled with ${ }^{33} \mathrm{P}$. To prepare a Myoc probe, plasmid containing the mouse Myoc cDNA was used as a template in a PCR with oligonucleotides 5'-GAATGAAGATTTGGCCAGGA-3' and 5'-ACCnerve.
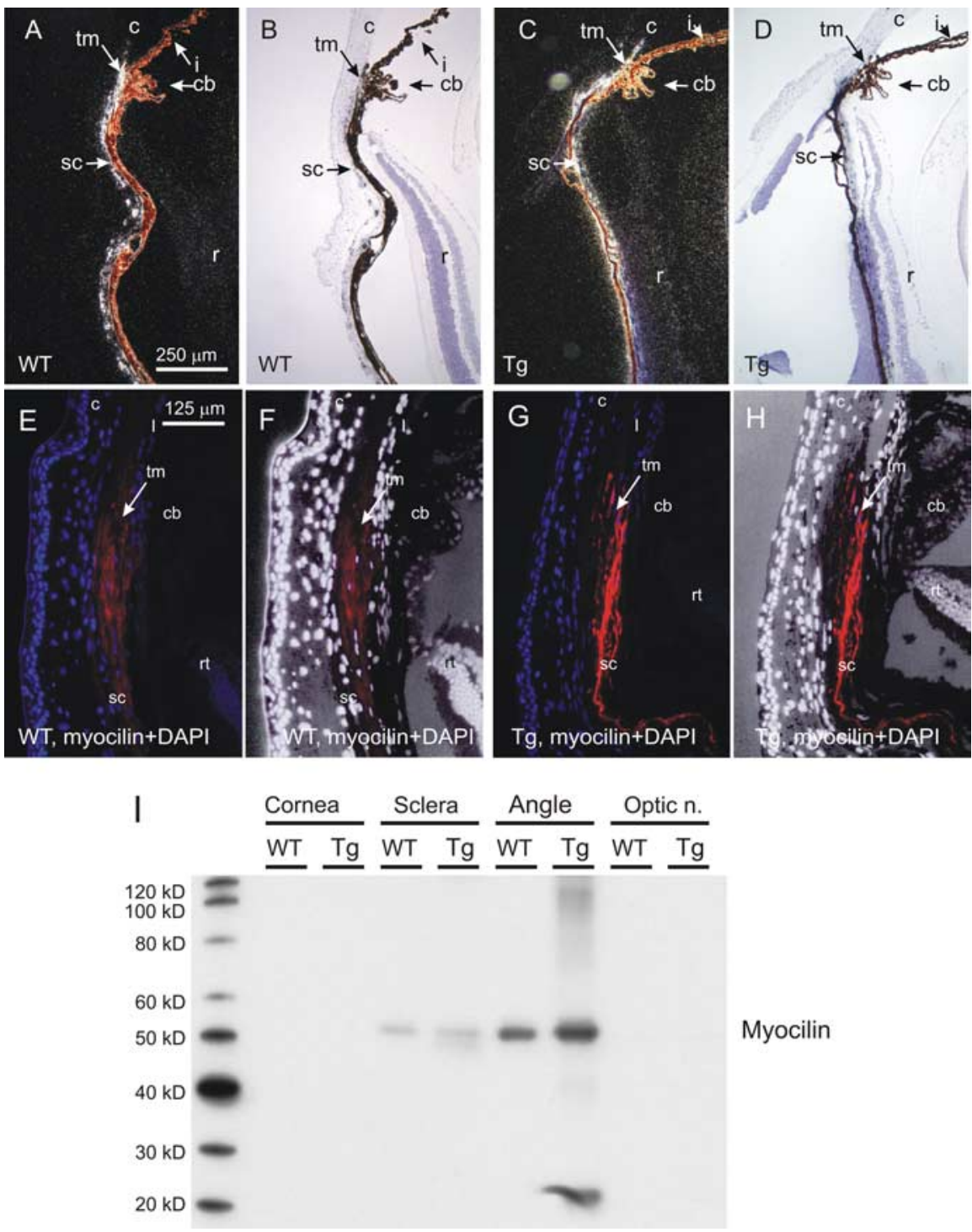

Figure 1. Myoc expression in the eyes of 8-month-old Wt and Tg mice. $A, C$, Radioactive in situ hybridization. Note similar levels of Myoc mRNA expression in the TM of $\operatorname{Tg}(\boldsymbol{C})$ and Wt $(\boldsymbol{A})$ mice. $\boldsymbol{B}, \boldsymbol{D}$, The same images as in $\boldsymbol{A}$ and $\boldsymbol{C}$ in the bright field. Sections were counterstained with hematoxylin. $\boldsymbol{E}-\boldsymbol{H}$, Myoc immunostaining. $\boldsymbol{E}, \boldsymbol{G}$, Note the higher levels of immunostaining in the TM/sclera morphological structures. Red, Myocilin; blue $(\boldsymbol{E}, \boldsymbol{G})$ and white $(\boldsymbol{F}, \boldsymbol{H})$, DAPI. No Myoc immunostaining was observed when primary

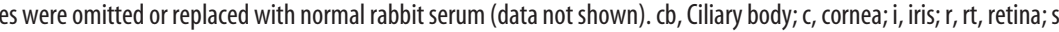
rotein per well were separated by SDS-PAGE, transferred to PVDF membrane, and stained with Myoc antibodies. Optic n., Optic

GTGTACAAGATGCCACA-3'. A PCR fragment with a length of $831 \mathrm{bp}$ was cloned into the pBluescript II KS(+/-) vector (Stratagene, La Jolla, CA). An antisense Myoc probe was prepared by in vitro transcription from the T7 promoter using the MAXIscript kit (Ambion, Austin, TX). In situ hybridization, washes, and autoradiography were done using a mRNAlocator kit (Ambion) according to manufacturer's specifications.

Immunohistochemistry. Mice were anesthetized with a mixture of ketamine $(100 \mathrm{mg} / \mathrm{kg})$ and xylazine $(10 \mathrm{mg} / \mathrm{kg})$ and perfused transcardially with $4 \%$ paraformaldehyde in $0.1 \mathrm{M} \mathrm{PBS}, \mathrm{pH} 7.4$, and the eyes were postfixed at $4^{\circ} \mathrm{C}$ for $2-4 \mathrm{~h}$ before processing for paraffin embedding or the whole-retina preparation. Deparaffinized $6 \mu \mathrm{m}$ sections and/or whole retinas were then incubated with primary antibodies for $1-2 \mathrm{~h}$ at room temperature or overnight at $4^{\circ} \mathrm{C}$. Whole retinas were always incubated overnight. The antibodies used were polyclonal rabbit antibodies to mouse Myoc, ATPase $\alpha-1$ (Upstate Biotechnology, Lake Placid NY), Brn3b (Santa Cruz Biotechnology, Santa Cruz, CA), GFAP (Chemicon, 

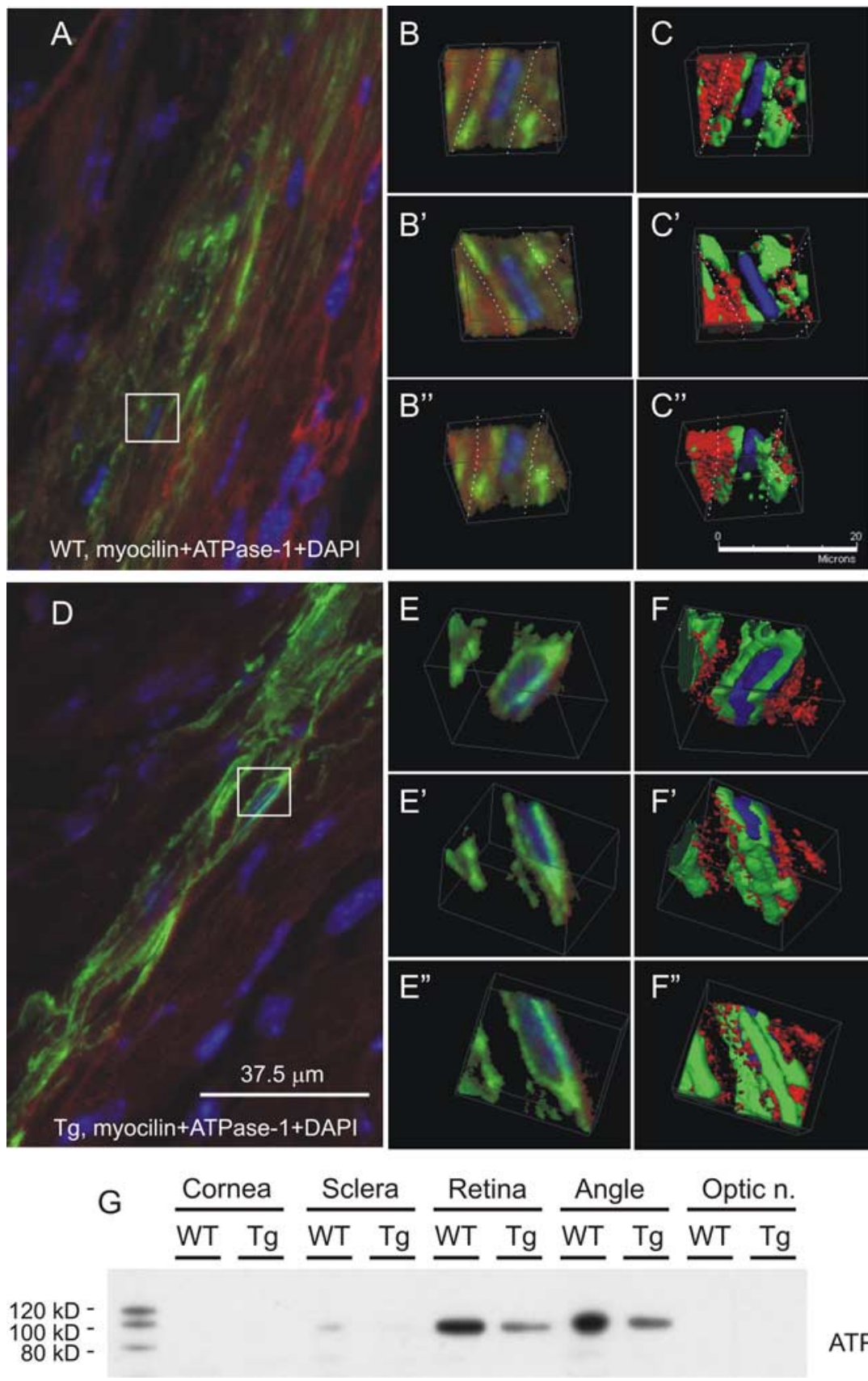

Figure 2. Subcellular localization of Myoc and ATPase-1 in the TM of Tg and Wt mice. Three-dimensional analysis of the eye sections of Wt $\left(\boldsymbol{A}-\boldsymbol{C}^{\prime \prime}\right)$ and $\operatorname{Tg}\left(\boldsymbol{D}-\boldsymbol{F}^{\prime \prime}\right)$ mice stained with antibodies against Myoc (green) and ATPase-1 (red) is shown. Cell nuclei were stained with DAPI (blue). Boxed areas in $\boldsymbol{A}$ and $\boldsymbol{D}$ are shown in three-dimensional projections in $\boldsymbol{B}-\boldsymbol{C}^{\prime \prime}$ and $\boldsymbol{E}-\boldsymbol{F}^{\prime \prime}$, respectively. Note that an increase in Myoc staining in Tg eyes was associated with a decrease in ATPase-1 immunostaining. $\mathbf{G}$, Western blot analysis of ATPase-1 contents in dissected eye tissues of Tg and Wt mice. Optic n., Optic nerve.

Temecula, CA), monoclonal mouse antibodies against NeuN (Chemicon), Nf-160 (Sigma, St. Louis, MO), and a mouse antibody against Nf-68 (Chemicon). Rabbit antiserum against mouse Myoc was received as described previously (Kim et al., 2001) and was affinity purified. Signal visualization was performed by incubating sections for $1 \mathrm{~h}$ at room temperature with an appropriate secondary antibody conjugated to CY3 or Alexa 488 fluorophores (1:200; Invitrogen, Eugene, OR) diluted in PBS containing $0.5 \%$ Triton X-100 and $0.2 \mu \mathrm{g} / \mathrm{ml}$ propidium iodide (PI) or 4',6-diamidino2-phenylindole (DAPI) (Invitrogen) for counterstaining.

Western blotting. Lysates from dissected cornea, retina, sclera, drainage structures, and optic nerve were separated by PAGE. Ten micrograms of each extract were loaded in each well. After separation and transfer to a
ATPase-1

polyvinylidene difluoride (PVDF) membrane, the blots were incubated with a rabbit polyclonal antibody against Myoc at a 1:2000 dilution. Horse anti-rabbit secondary antibodies conjugated to horseradish peroxidase (Vector Laboratories, Burlingame, CA) were used at a 1:5000 dilution. Detection was made using an $\mathrm{ECL}+$ kit (Amersham Biosciences, Piscataway, $\mathrm{NJ}$ ). The amounts of loaded protein were determined using a protein standard curve made after protein samples were run along with bovine serum albumin standards and blotted to a PVDF membrane that was stained with SYPRO Ruby (Invitrogen). For digital quantification, membranes were scanned using Typhoon 9410 Variable Mode Image (Amersham Biosciences) and analyzed using Image Pro Plus 5.1 (Media Cybernetics, Silver Spring, MD). All experiments were repeated at least two times.

IOP measurement. Mice were anesthetized with a mixture of ketamine $(100 \mathrm{mg} / \mathrm{kg})$ and xylazine $(10 \mathrm{mg} / \mathrm{kg})$. IOP was measured in anesthetized animals using a fiber-optic FTI-10 Signal Conditioner equipped with a fiber-optic pressure transducer (FISO Technologies, Montreal, Quebec, Canada) as described previously (Ahmed et al., 2003; Filippopoulos et al., 2006). The use of this technique was based on the assumption that mechanical properties of the cornea are essentially the same in $\mathrm{Wt}$ and $\mathrm{Tg}$ animals. IOP from each eye was recorded during a 2 min session, with four measurements taken at $30 \mathrm{~s}$ intervals within each session. The average of these four measurements was used to calculate an IOP value for each eye. Dacriose sterile eye irrigating solution (Novartis, Basel Switzerland) was topically applied before and after each IOP measurement. Statistical differences were analyzed by the Student's $t$ test.

Terminal deoxynucleotidyl transferasemediated biotinylated UTP nick end labeling. Apoptotic cell death was estimated by terminal deoxynucleotidyl transferase-mediated biotinylated UTP nick end labeling (TUNEL) assays using a Fluorescein ApopTag kit (Intergen, Purchase, NY) according to the manufacturer's instructions. For fluorescent counterstaining, TUNEL-labeled sections, or whole retinas, were mounted in Vectashield medium containing $1.5 \mu \mathrm{g} / \mathrm{ml}$ PI (Vector Laboratories). Selected TUNEL-labeled sections were double immunostained for NeuN.

Image analysis. Two- and three-dimensional images of whole-mount retinas were recorded with a confocal laser-scanning system in sequential scan mode (TCS SP2; Leica Microsystems, Exton, PA). Three-dimensional blind deconvolution and three-dimensional visualization were performed using a confocal configuration system (AutoDeblur/AutoVisualize version 8.0; AutoQuant Imaging, Watervliet, NY) For whole-mount retinas, images from each of the four retinal segments were randomly chosen to calculate the number of Brn3b- and NeuNpositive cells per an area of $750 \times 750 \mu \mathrm{m}$. This average of the four measurements was used to compare the different animals. The center of each image was $1845 \mu \mathrm{m}$ from the optic nerve head as shown in Figure 10. Two images of the peripheral retina, from opposite sides of each section, were used to analyze the number of Brn3b-, Nf68-, or DAPIpositive cells in the RGC layer, within $725 \mu \mathrm{m}$ of the retinal edge. The mean of two counts was used as the representative number of cells for 
each section. Every fifth section, cut not $>100$ $\mu \mathrm{m}$ from the optic nerve, was used for the analysis, thus providing measurements from three to six sections per eye. The average of these measurements was used to compare the difference between animals. Quantitations of Brn3band NeuN-positive cells in whole-mount retina and Brn3b-, Nf68-, and DAPI-positive cells in retinal sections were performed off-line using Image Pro Plus 5.1. Statistical differences in the number of labeled neurons were analyzed by the Student's $t$ test.

Electron and light microscopy. For electron and light microscopy studies, mouse eyes with $5 \mathrm{~mm}$ long stumps of optic nerve were enucleated and fixed in $4 \%$ glutaraldehyde in $0.15 \mathrm{M}$ phosphate buffer, $\mathrm{pH} 7.2$, at $4^{\circ} \mathrm{C}$ overnight. After dissection, the pieces of tissue containing the central retina attached to the optic nerve, or the eye irido-corneal angle, were dissected and placed in $1 \%$ osmium tetroxide. After dehydration and infiltration with propylene oxide alone and with propylene oxide mixed with epoxy, the pieces were embedded in a Ladd LX112 epoxy. Semithin $(1 \mu \mathrm{m})$ and ultrathin $(\sim 0.08 \mu \mathrm{m})$ sections for light and electron microscopy, respectively, were cut on an ultramicrotome using a diamond knife. Semithin sections were stained with a mixture of toluidine blue, methylene blue, and Azure II, $0.25 \%$ each in $1.0 \%$ sodium borate or with paraphenilene diamine ( $1 \%$ in 1:1 isopropanol:methanol mixture). For the latter, optic nerve samples were en block prestained with $2 \%$ uranyl acetate in $0.1 \mathrm{~m}$ sodium acetate and embedded in a Polybed 812/Araldite resin. Electron microscopy (EM) was performed using a Jeol (Tokyo, Japan) 1010 Transmission electron microscope equipped with digital imaging capabilities.

\section{Results}

\section{Generation of Tg mice expressing mutated mouse Myoc}

BAC DNA (clone \#16652) containing the full-length mouse Myoc gene, as well as 20 and $85.5 \mathrm{~kb}$ of the $5^{\prime}$-flanking and $3^{\prime}$-flanking sequences, respectively, was used for $\mathrm{Tg}$ mice production. Because available data suggest that pathogenesis of Myoc-related glaucoma is dependent on the expression of abnormal mutant protein, the Tyr423His point mutation was introduced into Myoc BAC DNA in vitro as described in Materials and Methods. Several lines of Tg mice, carrying mutated mouse Myoc BAC DNA, were developed. Real-time PCR analysis revealed one line containing two to three copies of the mutated Myoc gene, which was selected for additional analysis.

\section{Expression of Myoc and ATPase-1 in the eyes of Wt and Tg animals}

The relative proportion of mutated and Wt Myoc mRNA was estimated by cloning and sequencing PCR-amplified fragment of Myoc cDNA from eyes of Tg mice. This PCR fragment included the mutated Tyr423His site. Twenty-five percent of the 40 clones sequenced carried mutated Myoc cDNA. On the basis of this result, we concluded that the ratio between mutated and Wt Myoc mRNA was 1:3 in the eyes of Tg mice.

The distribution of mutated and Wt Myoc mRNA in the eye of $\mathrm{Tg}$ and Wt mice was studied by in situ hybridization. Our in situ hybridization procedure could not distinguish between $\mathrm{Wt}$ and mutated Myoc mRNA. In both Tg and Wt mice, Myoc mRNA was preferentially expressed in the trabecular meshwork (TM) and sclera (Fig. $1 A-D$ ), and at comparable levels. The similar levels of Myoc mRNA expression in angle tissues and sclera of Tg and $\mathrm{Wt}$ mice were confirmed using quantitative real-time PCR (data not shown).

The distribution of Myoc protein was first investigated by Western blotting using dissected eye tissues. Antibody against mouse Myoc recognized a band of $\sim 50 \mathrm{kDa}$ in tissues of the angle and sclera (Fig. 1I). A band of $\sim 20 \mathrm{kDa}$ was also observed in $\mathrm{Tg}$ but not Wt TM (Fig. 1I). Myoc levels were consistently higher in Tg TM compared with Wt TM (Fig. 1I). Digital chemifluorescence quantification of Myoc on Western blots showed that Myoc contents in the angle of Tg mice were twofold to threefold higher compared with their Wt littermates.

Distribution of the Myoc in the eye, by immunostaining, was similar to that for Myoc mRNA: Myoc was present mainly in the TM and sclera (Fig. $1 E-H$ ). Myoc immunostaining was two to four times more intense in the TM of Tg mice compared with $\mathrm{Wt}$ littermates (Fig. 1, compare $G, H$ with $E, F$ ), confirming the results of Western blotting analysis. This difference was observed consistently in animals of different ages, from 6 to 21 months. Not only the level but also the intracellular distribution of Myoc was different in the TM cells of Tg and Wt animals, as demonstrated by confocal three-dimensional analysis. In the TM of Tg animals, Myoc demonstrated cytoplasmic localization, filling intracellular space between the nucleus and plasma membrane, which was stained with membrane markers ATPase-1 (Fig. 2A$\left.C^{\prime \prime}\right)$. Myoc fluorescence in Wt cells was generally more diffused and significantly weaker; it was found farther from the nucleus and closer to plasma membrane with some signal located outside the TM cells in the extracellular space (Fig. $2 D-F^{\prime \prime}$ ). 


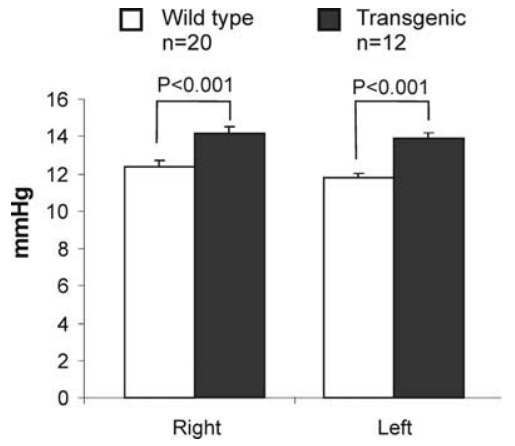

Figure 4. IOP elevation in the eyes of $\mathrm{Tg}$ mice. Results of IOP measurements in the right and left eyes of 12- to 18-month-old $\mathrm{Tg}$ and Wt mice are shown. Error bars indicate SE.

An increase in Myoc immunofluorescence in Tg TM was accompanied by a decrease in immunofluorescence for ATPase-1 (Fig. $2 A, D$ ). This observation was confirmed by Western blotting experiments that showed decreased amounts of ATPase- 1 in the TM of Tg animals compared with their Wt littermates (Fig. $2 G$ )

\section{Morphological analysis of the angle of the eye}

To determine whether accumulation of Wt and mutated Myoc in TM cells induces cell death in the eye angle region, we performed TUNEL staining on eye sections from $\mathrm{Tg}$ and $\mathrm{Wt}$ littermates of different ages (from 6 to 21 months old). We did not observe TUNEL-positive cells inside the TM in these experiments (data not shown). To determine whether the accumulation of Wt and mutated Myoc in TM cells induces morphological changes in the eye angle region, we analyzed semithin sections (Fig. $3 A, B, D, E$ ) and electron micrographs (Fig. $3 C, F$ ) of the TM from Tg mice (two pairs, 13 and 17 months old). This analysis did not reveal any significant pathological changes in the TM of Tg mice. However, we consistently observed the presence of detached cells in Schlemm's canal adjacent to the TM and breaks in the inner wall of Schlemm's canal in the four Tg eyes that we analyzed (Fig. $3 F$ ). Such pathological changes were not observed in the four control eyes analyzed (Fig. 3C).

\section{IOP measurements}

Mutations in the human MYOC gene often lead to IOP elevation. To check whether expression of mutated mouse Myoc may affect the aqueous humor balance, we measured
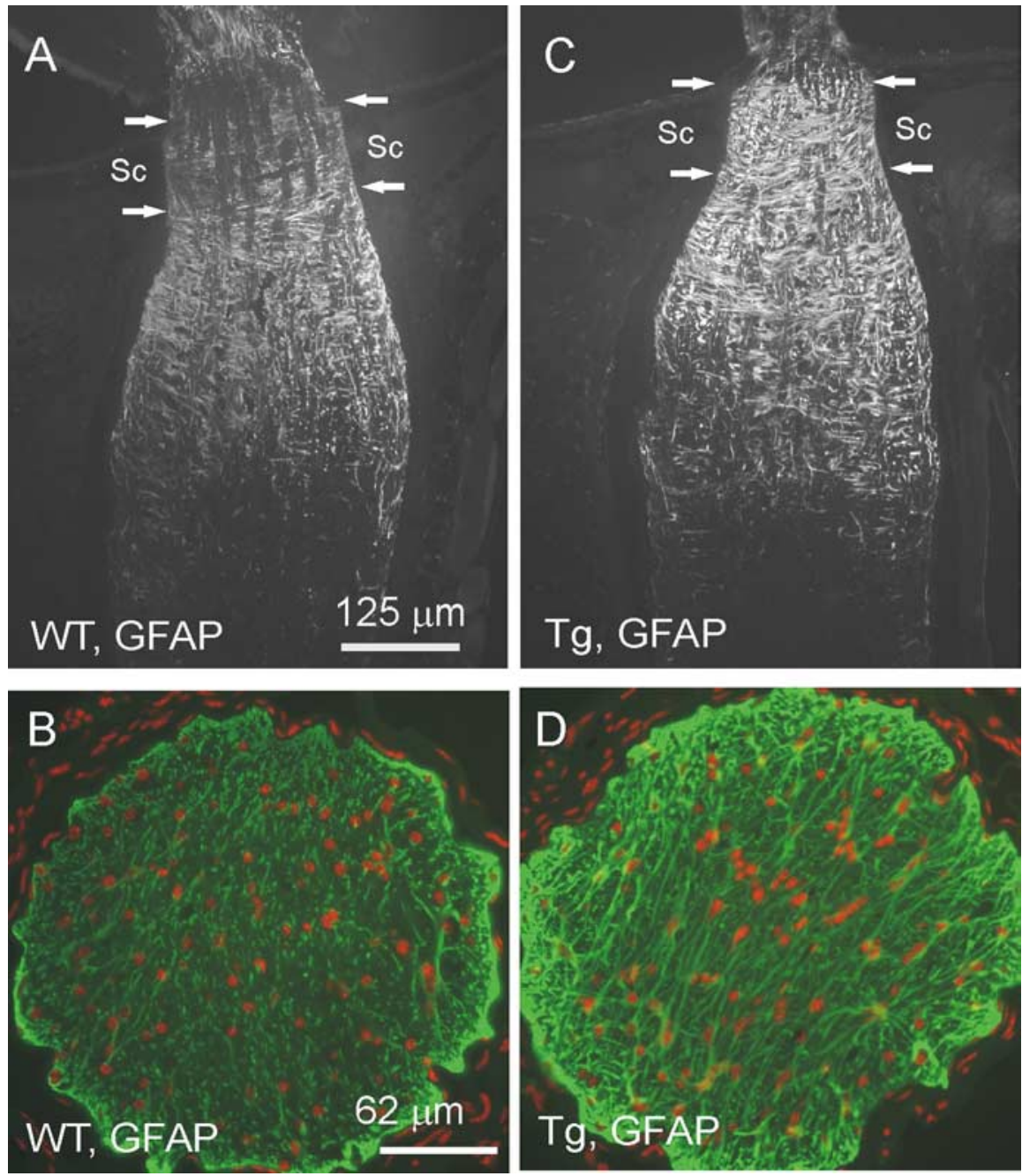

Figure 5. GFAP immunostaining of the optic nerve of $\operatorname{Tg}$ mice $(\boldsymbol{C}, \boldsymbol{D})$ and Wt littermates $(\boldsymbol{A}, \boldsymbol{B}) . \boldsymbol{A}, \boldsymbol{C}$, Longitudinal sections through optic nerves of 20-month-old mice nascent to the eyeball. $B, D$, Cross section through the optic nerve $0.5 \mathrm{~mm}$ from the eye ball. Green, GFAP; red, PI. Arrows indicate the part of the optic nerve where it passes through the sclera (Sc). Note the increased GFAP immunoreactivity in the optic nerve in Tg mice versus Wt littermates. Similar patterns of staining were obtained with three pairs of eyes.
IOP in Tg mice and their Wt littermates using a noninvasive applanation tonometer as described in Materials and Methods (Ahmed et al., 2003; Filippopoulos et al., 2006). IOP in the eyes of 12- to 18 -monthold Tg animals $(n=12)$ was $\sim 2 \mathrm{mmHg}$ higher than that in the eyes of Wt animals $(n=20)$. An increase in IOP was found both in the right eye $(14.1 \pm 0.3$ vs $12.4 \pm$ $0.3 ; p<0.001)$ and left eye $(13.9 \pm 0.4 \mathrm{vs}$ $11.7 \pm 0.3 ; p<0.001$ ) of Tg animals (Fig. 4). This difference was not dependent on age within the age interval studied.

\section{Morphological analysis of the optic nerve}

Because GFAP is upregulated in many neurodegenerative diseases, we first compared GFAP distribution in the optic nerve of Wt and Tg animals. GFAP staining of longitudinal sections of optic nerves showed an increase in astroglial immunoreactivity in Tg mice (Fig. $5 C$ ) compared with Wt littermates (Fig. 5A) at the scleral level. Immunostaining of transverse sections of the optic nerve, cut $\sim 0.5 \mathrm{~mm}$ behind the globe, showed predominant increase in GFAP immunoreactivity at the periphery of the optic nerve of $\mathrm{Tg}$ mice (Fig. 5D) compared with Wt littermates (Fig. 5B) (two pairs, 18 months old).

Degeneration of the optic nerve is one of the hallmarks of glaucoma. To analyze morphological changes in the optic nerve, semithin transverse sections were cut at $\sim 0.5 \mathrm{~mm}$ behind the globe and stained with a mixture of toluidine blue, methylene blue, and Azure II (Fig. 6A,D). Compared with Wt littermates (Fig. 6A), the optic nerve of 13-month-old Tg mice (Fig. $6 D)$ showed accumulation of darkly 
stained structures throughout the optic nerve, except for the peripheral areas, where patches of "empty" space without axons were observed. Staining of semithin sections with paraphenilene diamine confirmed the loss of axonal profiles at the optic nerve periphery (Fig. 6, compare $B$, $E)$ and revealed the presence of abnormally dark axonal profiles throughout the cross section (Fig. 6, compare $C, F$ ). EM also showed the loss of axonal profiles in peripheral areas of the $\mathrm{Tg}$ optic nerve, which then become filled with low-density material (Fig. 7, compare A,C). Other pathological features included the lack of normal axoplasmic fine structure and the presence of condensed, electron-dense axoplasm, myelin debris, or empty, swollen axonal profiles (Fig. 7, compare $A, B$ with $C$, $D)$, all characteristic features of degenerating axons in the optic nerve (Peters, 2002).

\section{Changes in GFAP expression in the peripheral retina of $\mathrm{Tg}$ mice}

GFAP is a glial marker abundantly expressed in astrocytes, but not usually in normal Müller cells. Our Western blotting data did not show a significant difference between 18-month-old Tg and Wt mice when we measured the GFAP contents from whole-retina preparations (data not shown). Similarly, we did not see profound changes in GFAP expression in the central parts of $\mathrm{Tg}$ retina by immunostaining. However, immunostaining of wholemount retinas for GFAP showed an increase in the thickness of GFAP fibers at the periphery of Tg retina (Fig. 8, compare $A, B)$. Analysis of the peripheral regions of the retina in eye sections from 8 - and 20month-old mice, stained for GFAP, indi-

cated that the increase in GFAP staining at the edges of Tg retinas is attributable to increased immunoreactivity in Müller cells but not astrocytes (Fig. 8, compare $C, D$ ).

\section{Neuronal fiber depletion in $\mathrm{Tg}$ retina}

To compare the distribution of neuronal fibers in $\mathrm{Tg}$ and $\mathrm{Wt}$ retinas, whole-mount retinas of 12 -month-old $\mathrm{Tg}$ and $\mathrm{Wt}$ mice were stained with antibody against neurofilament protein Nf160. Three-dimensional confocal analysis indicated the depletion of neuronal fibers in both the axonal fiber (Fig. 9E) and inner plexiform (Fig. $9 F$ ) layers of peripheral retina from $\mathrm{Tg}$ mice compared with Wt littermates (Fig. 9A,B). However, outer plexiform layers of Tg and Wt mice had comparable fiber densities (Fig. 9, compare $C, G$ ). Three-dimensional visualization analysis indicated the selective depletion of neuronal fiber in the axonal fiber and inner plexiform layers but not in the outer plexiform layer of $\mathrm{Tg}$ retinas (Fig. 9H) compared with the retinas of $\mathrm{Wt}$ littermates (Fig. 9D).

\section{Analysis of Tg RGCs degeneration}

Degeneration of the RGCs is characteristic feature of glaucoma. Immunostaining with antibodies against Brn3b, NeuN, and
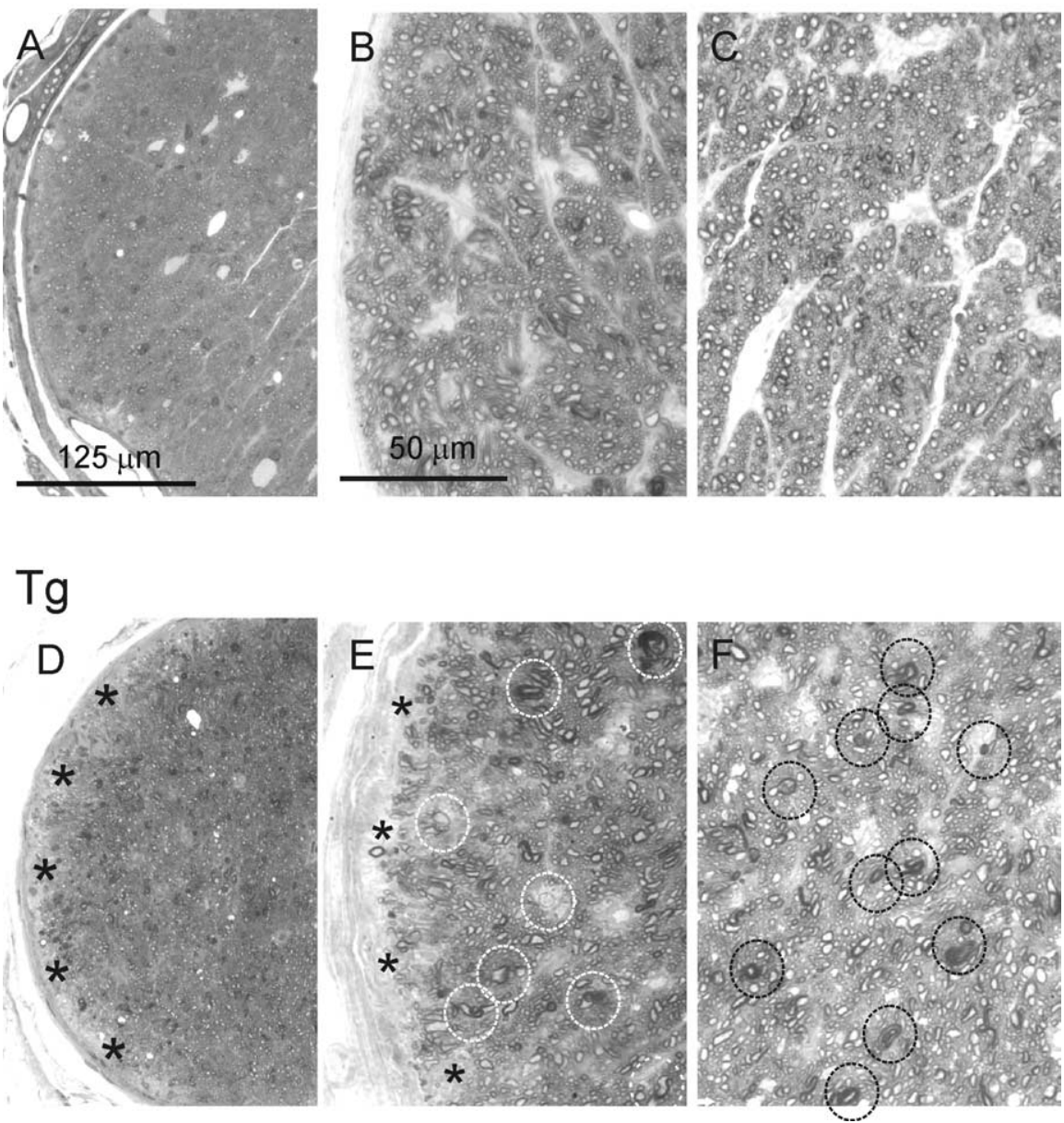

Figure 6. Degeneration of the optic nerve in $\operatorname{Tg}$ mice. $\boldsymbol{A}, \boldsymbol{D}$, Semithin sections through $\operatorname{Tg}(\boldsymbol{D})$ and Wt $(\boldsymbol{A})$ optic nerves of 3-month-old mice were stained with toluidine blue/methylene blue/Azure II. Degenerating axons in the Tg optic nerve were peripheral areas of the Tg but not Wt optic nerve. $\boldsymbol{B}, \boldsymbol{C}, \boldsymbol{E}, \boldsymbol{F}$, Paraphenilene diamine staining of semithin sections through the optic nerve of 13-month-old $\operatorname{Tg}(\boldsymbol{E}, \boldsymbol{F})$ and $\mathrm{Wt}(\boldsymbol{B}, \boldsymbol{C})$ mice. The degenerating axons in the Tg optic nerve had abnormally dark axonal profiles (circles in $\boldsymbol{E}$ and $\boldsymbol{F}$ ). The optic nerve periphery was characterized by the loss of axonal profiles (asterisks in $\boldsymbol{E}$ ).

NF68 was used to quantitatively estimate the size of the RGC population in $\mathrm{Tg}$ and $\mathrm{Wt}$ mice. When eye sections were used, Brn3b antibodies stained only $\sim 15 \%$ of DAPI-stained cells in the RGC layer. In the central retina, we did not find significant differences between $\mathrm{Wt}$ and $\mathrm{Tg}$ animals in the number of Brn3bstained cells (data not shown). However, there was an $\sim 20 \%$ loss of Brn3b-positive cells in the peripheral retina of Tg mice compared with Wt (Fig. 10, compare A, C; Fig. 10E) (8 months old). A decrease in the number of DAPI-stained cells in the RGC layer of Tg animals, compared with $\mathrm{Wt}$, was not statistically significant (Fig. 10, compare B, D; Fig. $10 E$ ).

Nf68 antibody stained $\sim 35-40 \%$ of the total DAPI-stained cell population in the RGC layer in eye sections. There was an $\sim 25 \%$ decrease in the number of NF68-positive cells in the peripheral RGC layer of Tg mice (Fig. $10 \mathrm{H}-J$ ) compared with $\mathrm{Wt}$ littermates (Fig. 10F, G,J).

Because quantitative analysis in the sections was limited to a small proportion of RGCs, we immunostained whole-mount retina preparations for various neuronal markers. There were $\sim 4500$ cells $/ \mathrm{mm}^{2}$ stained with DAPI (data not shown), $\sim 1900$ cells $/ \mathrm{mm}^{2}$ immunostained with NeuN (data not shown), $\sim 1600$ cells $/ \mathrm{mm}^{2}$ positive for Nf68 (data not shown), and $\sim 1200$ cells/ 

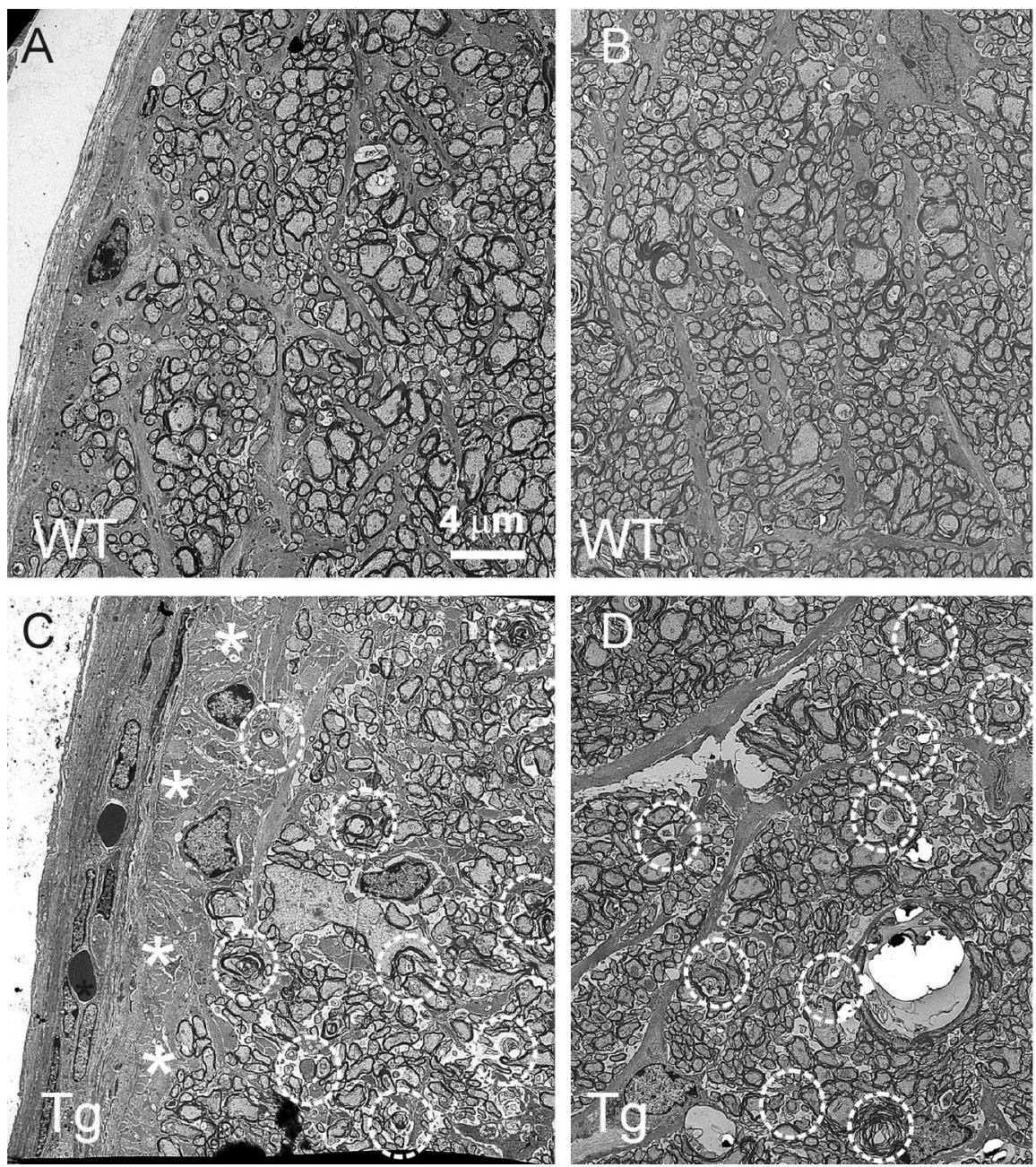

Figure 7. EM of optic nerve from 13-month-old $\operatorname{Tg}(\boldsymbol{C}, \boldsymbol{D})$ and $\mathrm{Wt}(\boldsymbol{A}, \boldsymbol{B})$ mice. Degenerating axons in the Tg optic nerve (circles) were identified by the lack of normal axoplasmic fine structure and the presence of condensed, electron-dense axoplasm, myelin debris, or empty, swollen axonal profiles. EM also showed the loss of axonal profiles in the peripheral areas (asterisks) that were instead filled up with low-density material (C).

$\mathrm{mm}^{2}$ positive for Brn3b (Fig. 11A) in the RGC layer of the peripheral retina. All cells expressing Brn3b also expressed Nf68 and NeuN. All cells expressing Nf68 also expressed NeuN (data not shown). Because NeuN is a specific neuronal marker, whereas DAPI labels all cells, we estimated that $>40 \%$ of all cells in the RGC layer are neurons. Confocal analysis of the soma and axons of RGCs in whole-mounted retina stained with Nf68 suggested that all cells stained with Nf68 are RGCs. This conclusion was supported by the fact that no cells stained for Nf68 were found outside of the RGC layer. This excludes misplaced amacrine cells, the only neurons in the RGC layer, which are not RGCs. Thus, we estimated that $\sim 35 \%$ of all cells in the RGC layer were RGCs. The other $5 \%$ of neuronal cells may be misplaced amacrine cells. If all cells expressing NeuN are defined as neurons, and all cells expressing Nf68 are define as RGCs, then Brn3b was present in $\sim 65 \%$ of neurons in the RGC layer and in $\sim 75 \%$ of RGCs.

We did not find significant changes in the number of Brn3bpositive cells in the central areas of Tg retinas when the image centers were located 615 and $1230 \mu \mathrm{m}$ from the optic nerve. However, we found that peripheral retinal areas of 12 -month-old $\mathrm{Tg}$ mice (image center located $1845 \mu \mathrm{m}$ from the optic nerve head) had $\sim 20 \%$ fewer RGCs than their Wt littermates $(648 \pm 25$ vs $503 \pm 24$ per area of $750 \times 750 \mu \mathrm{m}$; three pairs of retinas; $p<0.001)$. From this we concluded that there is a degeneration of RGCs in the peripheral retina of $\mathrm{Tg}$ mice.

\section{Degeneration of RGC nuclei}

Because the changes in the size of cell nuclei reflect the physiological and morphological status of neuronal cells, we performed volumetric analysis on RGC nuclei in whole-mount retina stained with Brn3b. Our data showed a $10-30 \%$ decrease in the volume (Fig. 12G) and up to a $20 \%$ decrease in the surface area (Fig. $12 \mathrm{H}$ ) of Brn3b-stained nuclei from 12month-old Tg mice (Fig. 12D-F') compared with those of Wt (Fig. 12A-C') (two pairs).

Considering that nuclei shrinkage could signal ongoing apoptosis, we performed TUNEL in whole-mount retinas. We did not find any TUNEL-positive cells in the RGC layer of Wt retinas ranging in age from 8 to 20 months (Fig. $13 A-C$ ). However, we did find 30-50 TUNELlabeled cells in the RGC layer of the wholemount Tg retinas (Fig. 13D-F). Most of the labeled cells were found in the peripheral retina (Fig. $13 D, E$ ). TUNEL staining of eye sections confirmed that TUNELpositive cells were located in the RGC but not in other layers of Tg retinas (data not shown).

\section{Discussion}

In the present study, we describe a genetic mouse model of POAG with the Myoc gene mutation implicated in glaucoma (Stone et al., 1997). Neither the absence of MYOC (Kim et al., 2001) nor elevated levels of MYOC in the eye drainage structures (Gould et al., 2004) lead to IOP elevation, and neither induces morphological changes in the eye. These and other data suggested that the expression of mutated MYOC is necessary for development of open-angle MYOC-related glaucoma. Therefore, we produced several lines of Tg mice expressing a mouse Tyr $423 \mathrm{His}$ Myoc mutant, corresponding to the human MYOC Tyr437His mutation. Here, we characterize one line of Tg animals in detail, but preliminary analysis of one additional $\mathrm{Tg}$ line gave similar results.

The DNA used to produce transgenic animals reproduced the expression pattern of the endogenous $\mathrm{Myoc}$, as shown by in situ hybridization. Although levels of Myoc mRNA were similar in the eyes of Tg and Wt animals, and mutated Myoc mRNA represented only $\sim 25 \%$ of the total Myoc mRNA, we observed a twofold to threefold increase in the level of Myoc protein in the drainage structures of Tg mice. Furthermore, detailed threedimensional confocal analysis demonstrated the intracellular accumulation of Myoc and its depletion in extracellular space in the $\mathrm{TM}$ of $\mathrm{Tg}$ animals. It appears that, similar to cell culture experiments, mutated Myoc is not secreted, forming complexes with 
Wt Myoc and preventing secretion of Wt Myoc. This results in the Myoc accumulation within cells. Although the retention of Wt Myoc by mutated Myoc has been reported in cell culture experiments (Jacobson et al., 2001; Joe et al., 2003; Malyukova et al., 2006), to our knowledge, this is the first report of such a phenomenon in an animal model.

In aging glaucoma patients, a significant loss of TM cells occurs by detachment from the trabeculae and subsequent removal of cell debris via Schlemm's canal (Gabelt and Kaufman, 2005). This may result in reduced outflow facility (Alvarado et al., 1984). Consistent with this, electron microscopic analysis indicated an increased incidence of TM cell detachment from the TM trabeculae in Tg animals. Additional experiments are necessary to quantitatively evaluate TM cell detachment in Tg animals. Expression of mutated MYOC in cell culture has been shown to inflict cytotoxic effects including a modified cellular morphology (Joe et al., 2003) and/or cell death (Liu and Vollrath, 2004). It has been proposed that mutated MYOC exerts its toxicity by accumulating in, and stressing, endoplasmic reticulum (Joe et al., 2003). Our TUNEL and EM data did not show apoptotic cell death inside the TM. This may be
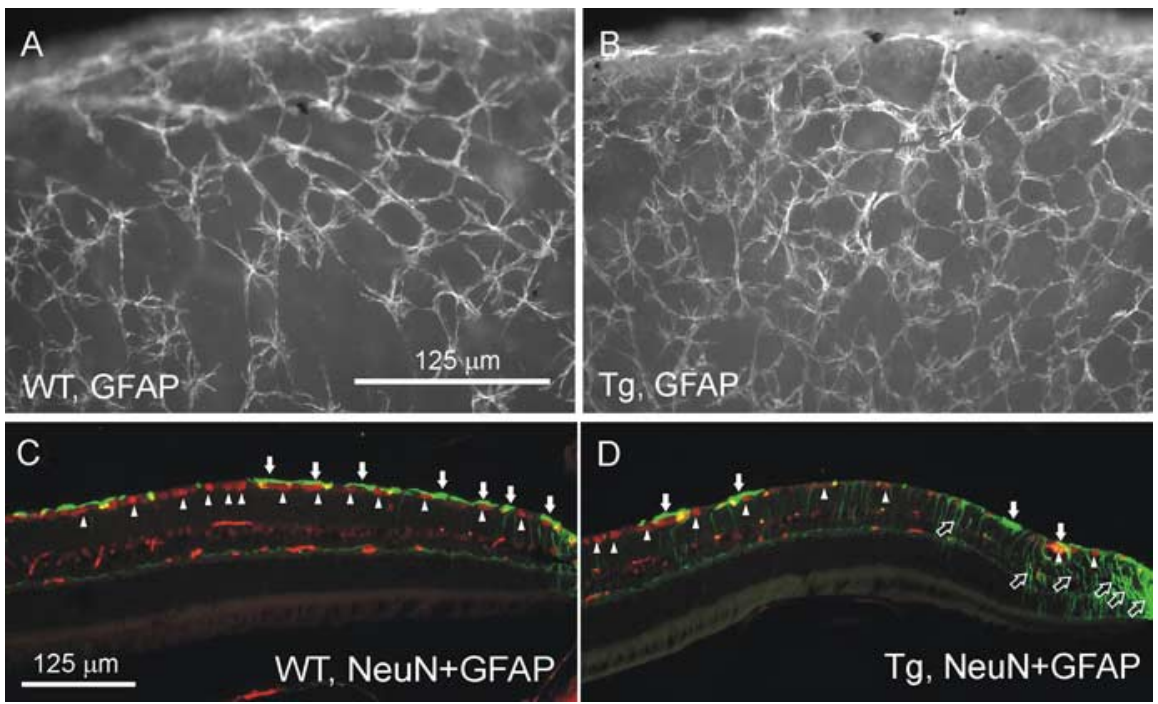

Figure 8. Changes in GFAP expression in the peripheral retina of Tg mice. $A, B$, An increase in the thickness of GFAP-labeled fibers on the surface of whole-mount retina from $\operatorname{Tg}$ mice $(\boldsymbol{B})$ compared with Wt littermates $(\boldsymbol{A})$. $\boldsymbol{C}, \boldsymbol{D}$, An increase in GFAP staining of Müller cells (open arrows) but not astrocytes (filled arrows) in the retina of 8-month-old Tg mice (D) compared with Wt littermates $(\boldsymbol{C})$. The loss of neuronal cells was also observed in $\mathrm{Tg}(\boldsymbol{D})$ but not in $\mathrm{Wt}(\boldsymbol{C})$ retinas as shown by double staining for NeuN (arrowheads). Green, GFAP; red, NeuN.

explained by much lower expression of mutated Myoc in the $\mathrm{TM}$ of Tg animals compared with the in vitro studies. Interestingly, our experiments demonstrated increased occurrence of apoptotic cell death in tissues surrounding the TM (our un-
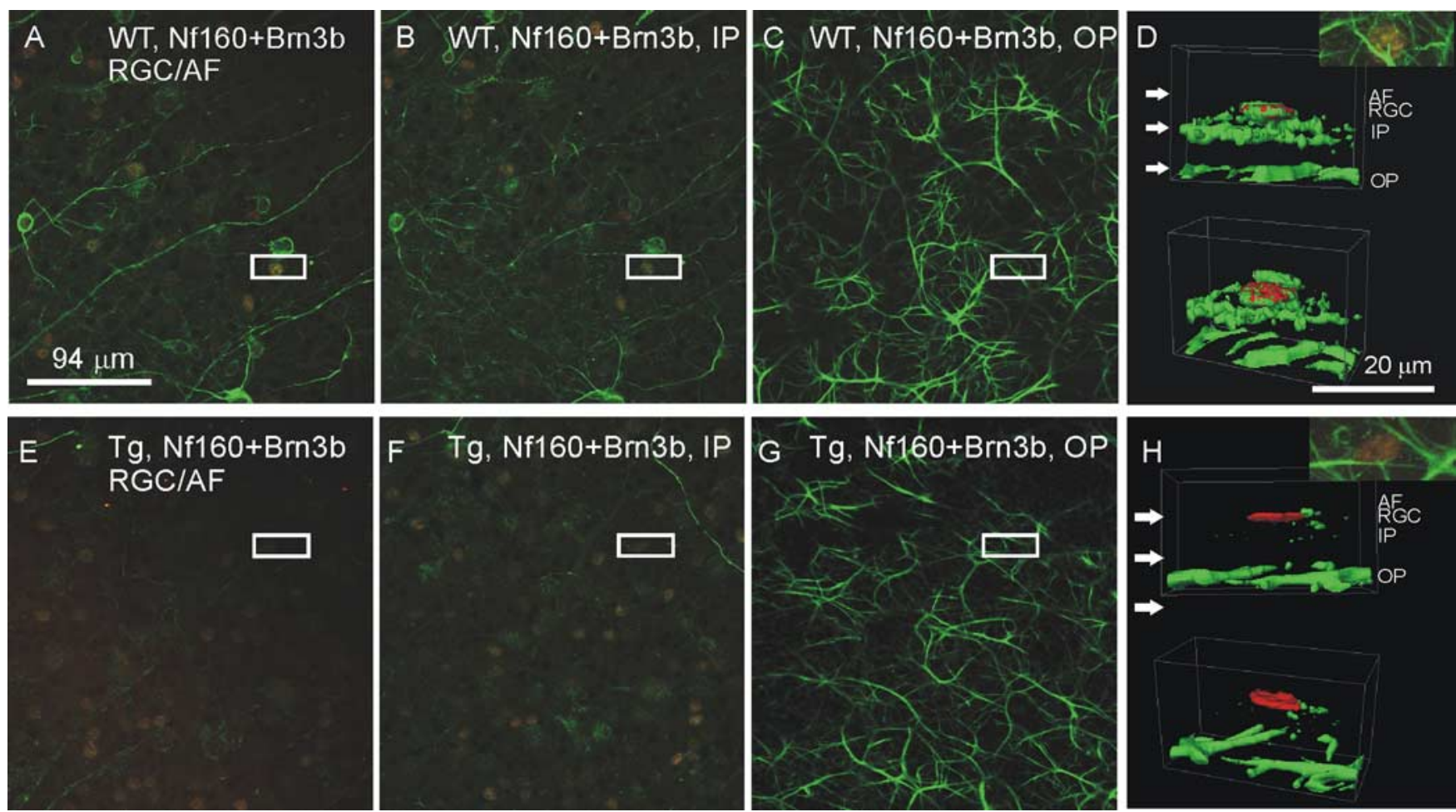

Figure 9. Neuronal fiber degeneration in the inner retina of 12-month-old Tg mice. Three-dimensional analysis of whole-mounted retinas, double labeled for Brn3b (red) and Nf160 (green), showed specific degeneration of nerve fibers in the axonal fiber (AF), RGC, and inner plexiform (IP) layers but not in the outer plexiform (OP) layer of Tg mice $(\boldsymbol{E}-\boldsymbol{H})$ compared with their Wt littermates $(\boldsymbol{A}-\boldsymbol{D}) . \boldsymbol{A}, \boldsymbol{E}$, Optical sections through the AF/RGC. B, $\boldsymbol{F}$, Optical sections through the IP. C, G, Optical sections through the OP. Boxed areas in $\boldsymbol{A}-\boldsymbol{G}$ were chosen for three-dimensional visualization at higher magnification, as shown in $\boldsymbol{D}$ and $\boldsymbol{H}$. Arrows in $\boldsymbol{D}$ and $\boldsymbol{H}$ indicate the approximate level of optic sections shown in $\boldsymbol{A}-\boldsymbol{C}$ and $\boldsymbol{E}-\boldsymbol{G}$, respectively. 

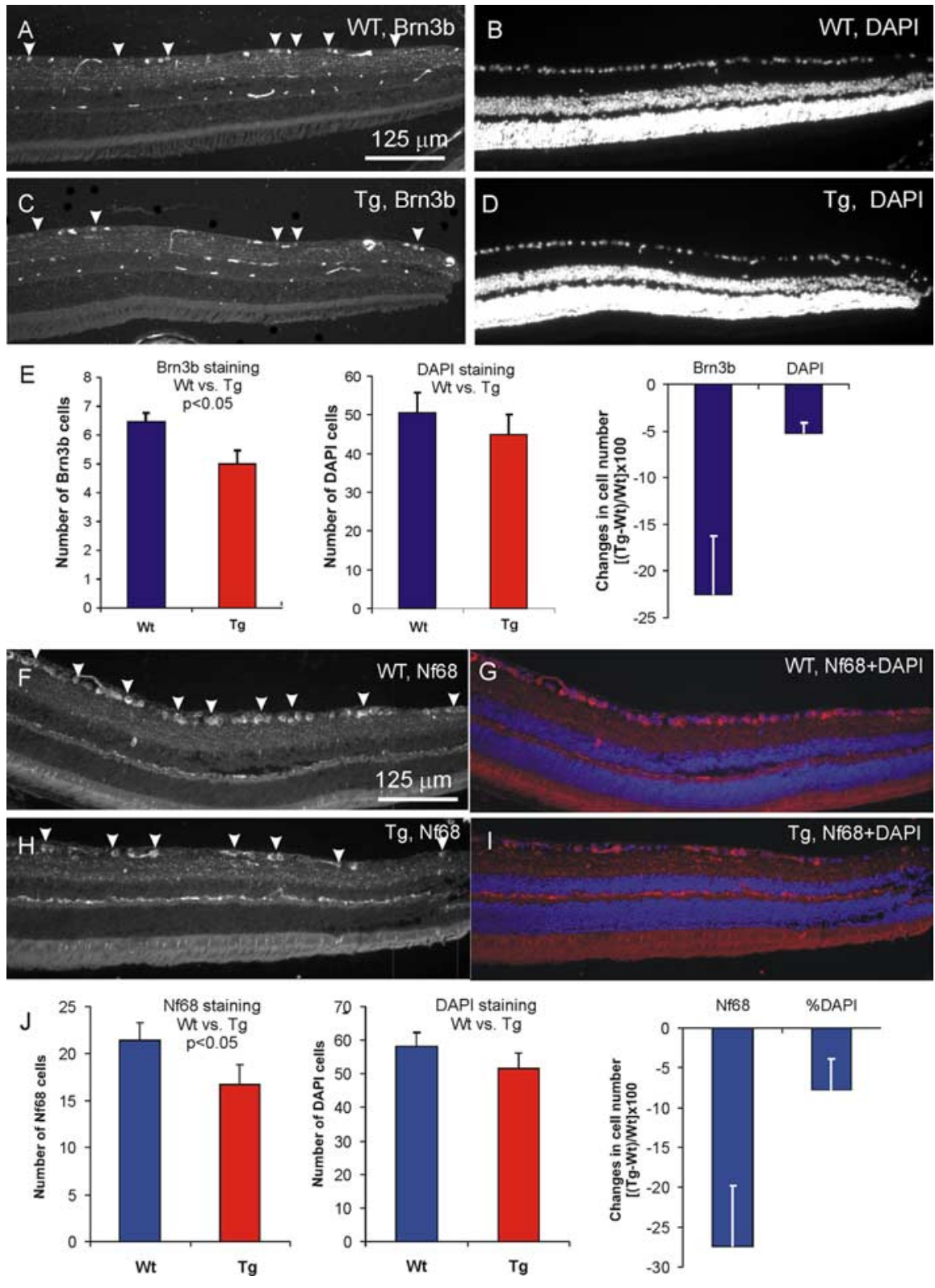

Figure 10. RGC degeneration in the peripheral retina of 8-month-old Tg mice. $A, C$, Brn3b-stained RGCS in Wt and Tg retinas, respectively. $\boldsymbol{B}, \boldsymbol{D}$, Images of the same areas in $\boldsymbol{A}$ and $\boldsymbol{C}$ showing DAPI staining. $\boldsymbol{E}$, Quantitative analysis of Brn3 and DAPI staining in the RGC layer of the peripheral retina of Wt and Tg mice. $\boldsymbol{F}, \boldsymbol{H}$, Nf68-stained $\mathrm{RGC} \sin \mathrm{Wt}(\boldsymbol{F})$ and $\mathrm{Tg}(\boldsymbol{H})$ peripheral retinas. $\boldsymbol{G}, \boldsymbol{I}, \boldsymbol{T}, \mathrm{Te}$ images of the same areas in $\boldsymbol{F}$ and $\boldsymbol{H}$ counterstained with DAPI (red, Nf68; blue, DAPI). J, Quantitative analysis of Nf68 and DAPI staining in Wt and Tg retinas. Error bars indicate SE.
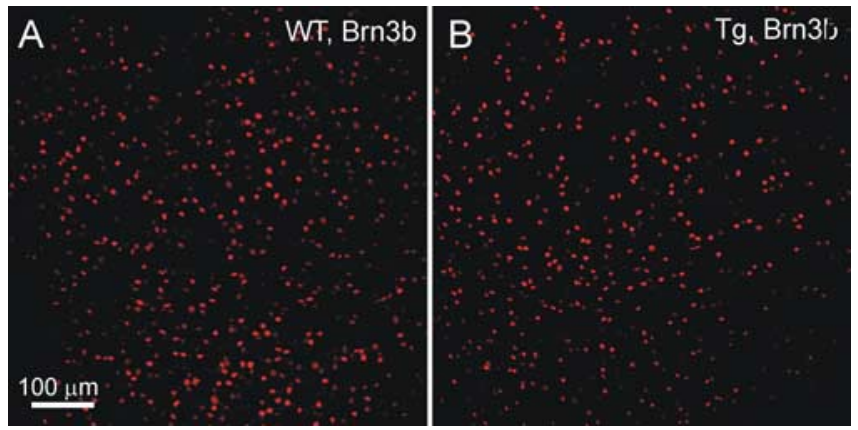

Figure 11. Immunofluorescence analysis of whole-mounted retinas of 12-month-old Tg mice. $\boldsymbol{A}, \boldsymbol{B}$, Representative images of the RGC layer stained with Brn3b (red) are shown. Our estimates showed that Brn3b antibody labeled $\sim 75 \%$ of the total RGC population. published observation). This suggests that Myoc accumulation affects surrounding tissue, either through changes in the extracellular environment or through mechanical stress induced by increased IOP.

Many studies demonstrated that there is a correlative relationship between glaucoma and IOP elevation (Weih et al., 2001; Kass et al., 2002). We observed moderate elevation of IOP by $\sim 2 \mathrm{mmHg}$ in both eyes of Tg mice compared with Wt littermates. This increase is smaller than that observed in patients with an analogous MYOC mutation (Alward et al., 1998). However, it has been shown that even a small decrease in IOP from 24.9 to 19.3 $\mathrm{mm}$ produces significant risk reduction for developing POAG in humans (Kass et al., 2002). Moreover, all IOP measurements were made between 9:00 A.M. and 2:00 P.M. Data of the literature (Savinova et al., 2001), and our own preliminary observations, indicate that IOP goes up at night and the IOP difference between Wt and Tg animals is higher at night (Y. Zhou and S. Tomarev, unpublished observation).

Increased Myoc in Tg TM was associated with a decrease in ATPase- 1 , which is highly expressed in the eye angle (Ahmed et al., 2004). A decrease in $\mathrm{Na}^{+}$gradient may result in several harmful events including cell overloading with calcium attributable to reversal of $\mathrm{Na}^{+} / \mathrm{Ca}^{2+}$ exchanger (Senatorov et al., 2000). Changes in ATPase-1 may also contribute to changes in IOP, because its major function is to transport $\mathrm{Na}^{+}$and $\mathrm{K}^{+}$across the membrane. Downregulation of ATPase has been demonstrated in transcription profiling of glaucoma patients (Golubnitschaja et al., 2002).

Axonal degeneration is a hallmark of glaucoma (Mabuchi et al., 2004). EM and analysis of semithin sections showed axonal degeneration at the periphery of the optic nerve in Tg mice. Degeneration of the optic nerve was accompanied by an increase in astrocyte GFAP immunoreactivity in the optic nerve at the scleral and post-scleral levels. This increase was most significant at the periphery of the optic nerve where degeneration of axons occurred. A link between astroglyosis and axonal degeneration may be suggested, because glial activation has been observed previously in many neurodegenerative disorders including glaucoma.

Changes in the RGC structure can be characterized based on their neurofilament organization (Ruiz-Ederra et al., 2004). Assessment of a dendritic and axonal degeneration in the RGC layer revealed depletion of neuronal fibers in both the neural fiber layer (NFL) and inner plexiform layer, which are enriched by dendrites and axons belonging or connecting to RGCs. However, only minor changes were found in outer plexiform layer, which mostly 
consists of fibers which do not belong to, or contact RGCs. These data correspond well to observations in glaucoma patients. Matsumoto et al. (2003) used scanning laser polarimetry to show that a decrease in NFL thickness precedes visual changes in both POAG and normal-tension glaucoma. Moreover, a detailed optical coherence tomography analysis of retina in glaucomatous eyes has shown selective decrease in thickness of the NFL, retinal ganglion cell layer, and inner plexiform layer, whereas no changes were found in the outer plexiform layer (Ishikawa et al., 2005).

Quantitative analysis of immunostained sections and whole-mount retinas from Tg mice indicated depletion of RGCs in the peripheral retina, without significant cell loss in the central retina. These observations are similar with those in glaucoma. Glaucoma most often affects peripheral visual function in its early stages, whereas deterioration of the central retina can be seen only at later stages of the disease (Foster et al., 2002). Moreover, in the human glaucomatous eye, RGCs and their axons die without affecting any other neurons (Quigley, 1999). Loss of RGCs in Tg mice was less pronounced than that in DBA/2 mice, which develop a progressive form of secondary angle-closure glaucoma (John et al., 1998). By the age of 15 months, there is an $~ 50 \%$ decrease in the number of RGCs in total retinas of DBA/2NNia mice compared with C57BL/6 mice (Danias et al., 2003). Enhanced damage of the RGC layer in the $\mathrm{DBA} / 2$ strain, compared with our $\mathrm{Tg}$ mice, correlates with a more dramatic increase in IOP, which, in most DBA/2J mice was 6-7 $\mathrm{mmHg}$ higher than in control mice by the age of 9 months (Libby et al., 2005).

Changes in the intensity of GFAP immunoreactivity in glial cells has been reported in the glaucomatous retina (Wang et al., 2002). In our experiments, we found little changes in GFAP immunoreactivity in astrocytes from $\mathrm{Tg}$ retina; however, we did observe an increase in GFAP immunoreactivity in Müller cells at the most peripheral parts of the retina. Similar to that, a decrease in GFAP immunoreactivity of astroglia and an increase in immunoreactivity of the Müller cells have been observed in retinas of rats with elevated IOP caused by episcleral vein cauterization (Kanamori et al., 2005).

Previous data suggest that the loss of RGCs in glaucoma occurs by apoptosis (Quigley, 1999). In the retina of Tg but not Wt mice, we detected apoptotic cells in the RGC layer. Most of the apoptotic cells were found in the peripheral retina, which might explain the loss of RGCs at the periphery of Tg retinas and optic nerves. Moreover, comparative confocal three-dimensional analysis of Brn3b-labeled RGCs in peripheral retina demonstrated a significant decrease in the size of the nuclei of RGCs in Tg mice. The shrinkage of nuclei is a characteristic feature of apoptosis (Rogalinska, 2002) and may precede apoptotic cell death of RGCs. Considering that there is a strict correlation between the sizes of soma and nucleus (Villena et al., 1997), the smaller nuclear size in Tg RGCs can also be an indication of the preferential death of larger RGCs, which are selectively vulnerable in glaucoma (Quigley, 1999).

At present, we do not fully understand how the expression of mutated Myoc leads to a moderate but persistent increase in IOP, axonal degeneration in the optic nerve, and RGC death through apoptosis. Nevertheless, these pathological changes have to be the result of mutated Myoc expression in the eye, because expression of even higher levels of Wt Myoc in the angle tissues of $\mathrm{Tg}$ mice did not produce such effects (Gould et al., 2004). The observed pathological changes are all characteristic 

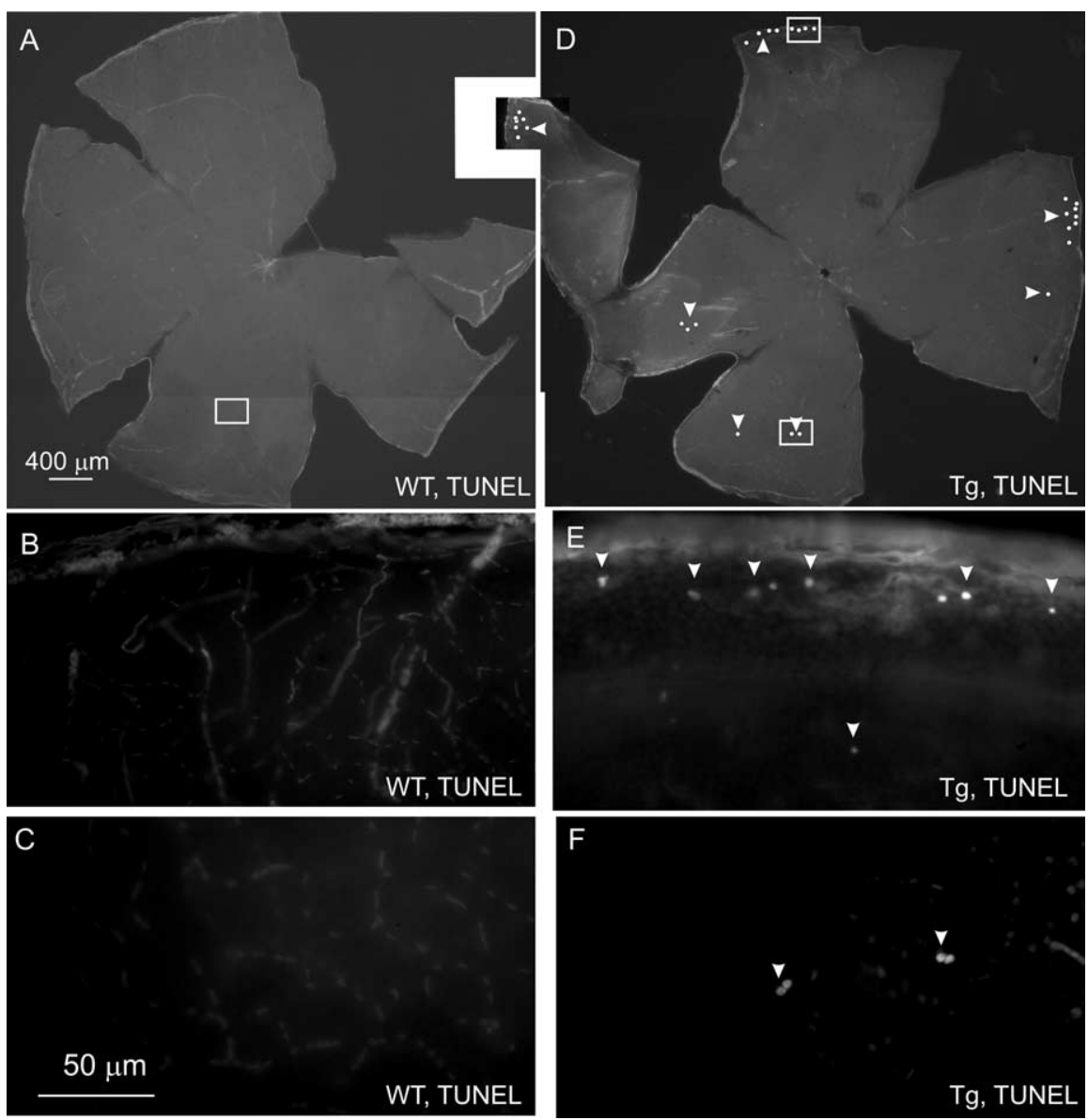

Figure 13. Apoptotic cell death in the RGC layer in the peripheral retina of $\operatorname{Tg}$ mice. $A, D, L$ Lw-magnification montages of whole-mount retinas of 14-month-old Wt $(\boldsymbol{A})$ and $\mathrm{Tg}(\boldsymbol{D})$ mice to show localization of TUNEL-positive cells. Each dot represents two to five labeled cells. $\boldsymbol{B}, \boldsymbol{C}, \boldsymbol{F}, \boldsymbol{G}$, Boxed areas in $\boldsymbol{A}$ and $\boldsymbol{D}$ are shown at higher magnification in $\boldsymbol{B}$ and $\boldsymbol{C}$ and $\boldsymbol{F}$ and $\boldsymbol{G}$, respectively. Arrowheads show TUNEL-positive cells.

features of open-angle glaucoma. Thus, Tg mice expressing mutated Myoc, under control of its own promoter, represent a genetic model of POAG and might be used to address several fundamental questions in glaucoma.

\section{References}

Ahmed E, Ma J, Rigas I, Hafezi-Moghadam N, Iliaki E, Gragoudas ES, Miller JW, Adamis AP (2003) Non-invasive tonometry in the mouse. Paper presented at the Annual Meeting of The Association for Research in Vision and Ophthalmology. Fort Lauderdale, FL, May.

Ahmed F, Torrado M, Zinovieva RD, Senatorov VV, Wistow G, Tomarev SI (2004) Gene expression profile of the rat eye iridocorneal angle: NEIBank expressed sequence tag analysis. Invest Ophthalmol Vis Sci 45:3081-3090.

Alvarado J, Murphy C, Juster R (1984) Trabecular meshwork cellularity in primary open-angle glaucoma and nonglaucomatous normals. Ophthalmology 91:564-579.

Alward WL, Fingert JH, Coote MA, Johnson AT, Lerner SF, Junqua D, Durcan FJ, McCartney PJ, Mackey DA, Sheffield VC, Stone EM (1998) Clinical features associated with mutations in the chromosome 1 openangle glaucoma gene (GLC1A). N Engl J Med 338:1022-1027.

Court DL, Swaminathan S, Yu D, Wilson H, Baker T, Bubunenko M, Sawitzke J, Sharan SK (2003) Mini-lambda: a tractable system for chromosome and BAC engineering. Gene 315:63-69.

Danias J, Lee KC, Zamora M-F, Chen B, Shen F, Filippopoulos T, Su Y, Goldblum D, Podos SM, Mittag T (2003) Quantitative analysis of retinal ganglion cell (RGC) loss in aging DBA/2NNia glaucomatous mice: comparison with RGC loss in aging C57/BL6 mice. Invest Ophthalmol Vis Sci 44:5151-5162.
Filippopoulos T, Matsubara A, Danias J, Huang W, Dobberfuhl A, Ren L, Mittag T, Miller JW, Grosskreutz CL (2006) Predictability and limitations of non-invasive murine tonometry: comparison of two devices. Exp Eye Res 83:194-201.

Fingert JH, Stone EM, Sheffield VC, Alward WL (2002) Myocilin glaucoma. Surv Ophthalmol 47:547-561.

Foster PJ, Buhrmann R, Quigley HA, Johnson GJ (2002) The definition and classification of glaucoma in prevalence surveys. Br J Ophthalmol 86:238-242.

Gabelt BT, Kaufman PL (2005) Changes in aqueous humor dynamics with age and glaucoma. Prog Retin Eye Res 24:612-637.

Golubnitschaja O, Wunderlich K, Decker C, Monkemann H, Schild HH, Flammer J (2002) Molecular imaging of perfusion disturbances in glaucoma. Amino Acids 23:293-299.

Gould DB, Miceli-Libby L, Savinova OV, Torrado M, Tomarev SI, Smith RS, John SW (2004) Genetically increasing Myoc expression supports a necessary pathologic role of abnormal proteins in glaucoma. Mol Cell Biol 24:9019-9025.

Ishikawa H, Stein DM, Wollstein G, Beaton S, Fujimoto JG, Schuman JS (2005) Macular segmentation with optical coherence tomography. Invest Ophthalmol Vis Sci 46:2012-2017.

Jacobson N, Andrews M, Shepard AR, Nishimura D, Searby C, Fingert JH, Hageman G, Mullins R, Davidson BL, Kwon YH, Alward WL, Stone EM, Clark AF, Sheffield VC (2001) Nonsecretion of mutant proteins of the glaucoma gene myocilin in cultured trabecular meshwork cells and in aqueous humor. Hum Mol Genet 10:117-125.

Ji J, Chang P, Pennesi ME, Yang Z, Zhang J, Li D, Wu SM, Gross RL (2005) Effects of elevated intraocular pressure on mouse retinal ganglion cells. Vis Res 45:169-179.

Joe MK, Sohn S, Hur W, Moon Y, Choi YR, Kee C (2003) Accumulation of mutant myocilins in ER leads to ER stress and potential cytotoxicity in human trabecular meshwork cells. Biochem Biophys Res Commun 312:592-600.

John SW, Smith RS, Savinova OV, Hawes NL, Chang B, Turnbull D, Davisson M, Roderick TH, Heckenlively JR (1998) Essential iris atrophy, pigment dispersion, and glaucoma in DBA/2J mice. Invest Ophthalmol Vis Sci 39:951-962.

John SW, Anderson MG, Smith RS (1999) Mouse genetics: a tool to help unlock the mechanisms of glaucoma. J Glaucoma 8:400-412.

Kanamori A, Nakamura M, Nakanishi Y, Yamada Y, Negi A (2005) Longterm glial reactivity in rat retinas ipsilateral and contralateral to experimental glaucoma. Exp Eye Res 81:48-56.

Kass MA, Heuer DK, Higginbotham EJ, Johnson CA, Keltner JL, Miller JP, Parrish II RK, Wilson MR, Gordon MO (2002) The ocular hypertension treatment study: a randomized trial determines that topical ocular hypotensive medication delays or prevents the onset of primary open-angle glaucoma. Arch Ophthalmol 120:701-713.

Kim BS, Savinova OV, Reedy MV, Martin J, Lun Y, Gan L, Smith RS, Tomarev SI, John SW, Johnson RL (2001) Targeted disruption of the myocilin gene $(M y o c)$ suggests that human glaucoma-causing mutations are gain of function. Mol Cell Biol 21:7707-7713.

Libby RT, Anderson MG, Pang I-H, Robinson ZH, Savinova OV, Cosma IM, Snow A., Wilson LA, Smith RS, Clark AF, John SWM (2005) Inherited glaucoma in DNA/2J mice: pertinent disease features for studying the neurodegeneration. Vis Nuerosci 22:637-648.

Liu Y, Vollrath D (2004) Reversal of mutant myocilin non-secretion and cell killing: implications for glaucoma. Hum Mol Genet 13:1193-1204.

Mabuchi F, Aihara M, Mackey MR, Lindsey JD, Weinreb RN (2004) Re- 
gional optic nerve damage in experimental mouse glaucoma. Invest Ophthalmol Vis Sci 45:4352-4358.

Malyukova I, Lee H-S, Fariss RN, Tomarev SI (2006) Mutated mouse and human myocilins have similar properties and do not block general secretory pathway. Invest Ophthalmol Vis Sci 47:206-212.

Matsumoto C, Shirato S, Haneda M, Yamashiro H, Saito M (2003) Study of retinal nerve fiber layer thickness within normal hemivisual field in primary open-angle glaucoma and normal-tension glaucoma. Jpn J Ophthalmol 47:22-27.

Peters A (2002) The effects of normal aging on myelin and nerve fibers: a review. J Neurocytol 31:581-593.

Quigley HA (1999) Neuronal death in glaucoma. Prog Retin Eye Res 18:39-57.

Rogalinska M (2002) Alterations in cell nuclei during apoptosis. Cell Mol Biol Lett 7:995-1018.

Ruiz-Ederra J, Garcia M, Hicks D, Vecino E (2004) Comparative study of the three neurofilament subunits within pig and human retinal ganglion cells. Mol Vis 10:83-92.

Savinova OV, Sugiyama F, Martin JE, Tomarev SI, Paigen BJ, Smith RS, John SW (2001) Intraocular pressure in genetically distinct mice: an update and strain survey. BMC Genet 2:12.

Senatorov VV, Stys PK, Hu B (2000) Regulation of $\mathrm{Na}+, \mathrm{K}+$-ATPase by persistent sodium accumulation in adult rat thalamic neurones. J Physiol (Lond) 525:343-353.

Stone EM, Fingert JH, Alward WL, Nguyen TD, Polansky JR, Sunden SL, Nishimura D, Clark AF, Nystuen A, Nichols BE, Mackey DA, Ritch R, Kalenak JW, Craven ER, Sheffield VC (1997) Identification of a gene that causes primary open angle glaucoma. Science 275:668-670.

Swaminathan S, Ellis HM, Waters LS, Yu D, Lee EC, Court DL, Sharan SK (2001) Rapid engineering of bacterial artificial chromosomes using oligonucleotides. Genesis 29:14-21.

Tomarev SI, Wistow G, Raymond V, Dubois S, Malyukova I (2003) Gene expression profile of the human trabecular meshwork: NEIBank sequence tag analysis. Invest Ophthalmol Vis Sci 44:2588-2596.

Villena A, Diaz F, Requena V, Chavarria I, Rius F, Perez de Vargas I (1997) Quantitative morphological changes in neurons from the dorsal lateral geniculate nucleus of young and old rats. Anat Rec 248:137-141.

Wang L, Cioffi GA, Cull G, Dong J, Fortune B (2002) Immunohistologic evidence for retinal glial cell changes in human glaucoma. Invest Ophthalmol Vis Sci 43:1088-1094.

Weih LM, Mukesh BN, McCarty CA, Taylor HR (2001) Association of demographic, familial, medical, and ocular factors with intraocular pressure. Arch Ophthalmol 119:875-880.

Weinreb RN, Lindsey JD (2005) The importance of models in glaucoma research. J Glaucoma 14:302-304. 